\title{
A classical swine fever virus E2 fusion protein produced in plants elicits a neutralizing humoral immune response in mice and pigs
}

\author{
Youngmin Park $\cdot$ Sangmin Lee $\cdot$ Hyangju Kang $\cdot$ Minhee Park $\cdot$ \\ Kyungmin Min • Nam Hyung Kim • Sungmin Gu • Jong Kook Kim • \\ Dong-Jun An $\cdot$ SeEun Choe $\cdot$ Eun-Ju Sohn
}

Received: 13 January 2020/Revised: 1 April 2020/Accepted: 14 April 2020/Published online: 22 April 2020

(C) The Author(s) 2020

\begin{abstract}
Classical swine fever (CSF) is one of the most important viral diseases of swine worldwide. Although live or attenuated virus vaccines have been used to control CSFV, it is difficult to distinguish vaccinated pigs from infected pigs; this leads to restrictions on import and export. Subunit vaccines based on the CSFV E2 glycoprotein have been developed using baculovirus or insect cell systems, but some weaknesses remain. Here, we describe production of an E2 recombinant protein using a Nicotiana benthamiana plant expression system. To do this, we took advantage of the ability of the swine Fc domain to increase solubility and stability of the fusion protein and to strengthen immune responses in target animals. $N$. benthamiana expressed high amounts of $\mathrm{pFc} 2$-fused E2 proteins, which were isolated and purified by affinity chromatography to yield a high pure recombinant protein in a cost-
\end{abstract}

Electronic supplementary material The online version of this article (https://doi.org/10.1007/s10529-020-02892-3) contains supplementary material, which is available to authorized users.

Y. Park $\cdot$ S. Lee $\cdot$ H. Kang $\cdot$ M. Park $\cdot$ K. Min ·

N. H. Kim · S. Gu · J. K. Kim · E.-J. Sohn $(\bowtie)$

BioApplications Inc., Pohang Techno Park Complex, 394

Jigok-ro Nam-gu, Pohang, Korea

e-mail: ejsohn@postech.ac.kr

D.-J. An · S. Choe

Virus Disease Division, Animal and Plant Quarantine

Agency, Gimcheon 39660, Gyeongbuk, Korea effective manner. Native-polyacrylamide gel electrophoresis and size exclusion chromatography confirmed that the pmE2:pFc2 fusion exists as a multimer rather than as a dimer. Injection of recombinant pmE2 protein into mice or piglets generated anti-pmE2 antibodies with efficient neutralizing activity against CSFV. These results suggest that a purified recombinant E2 protein produced in $N$. benthamiana generates high titers of neutralizing antibodies in vivo; as such, the protein could be developed as a subunit vaccine against CSFV.

Keywords Nicotiana benthamiana Classical swine fever virus · DIVA concept - Subunit vaccine .

Molecular farming $\cdot$ Fc-fusion protein

$\begin{array}{ll}\text { Abbreviations } \\ \text { CSFV } & \begin{array}{l}\text { Classical swine fever virus } \\ \text { DIVA }\end{array} \\ & \begin{array}{l}\text { Differentiating infected from vaccinated } \\ \text { animals }\end{array} \\ \text { ER } & \text { Endoplasmic reticulum } \\ \text { CBD } & \text { Cellulose-binding domain } \\ \text { BSA } & \text { Bovine serum albumin } \\ \text { MLV } & \text { Modified live vaccines } \\ \text { PCR } & \text { Polymerase chain reaction }\end{array}$




\section{Introduction}

Classical swine fever (CSF), a highly contagious and serious disease of pigs (Edwards et al. 2000), is caused by the CSF virus (CSFV), which is a positive-strand RNA virus belonging to the Pestivirus genus within the Flaviviridae family (Moennig 2000). The disease is endemic in Asia, Eastern Europe, and the Americas, as well as in some African countries (Greiser-Wilke et al. 2000; Tu et al. 2001; Deng et al. 2005; Cha et al. 2007; Postel et al. 2013). In Korea, live vaccines have been used traditionally to control swine fever where all pigs must be vaccinated early in life (Lim et al. 2016). Although the vaccine works and is inexpensive, it lacks stability, and it is hard to distinguish between pigs infected with swine fever and pigs that have been vaccinated (the DIVA concept; differentiating infected from vaccinated animals), which limits the pig trade. Because of this, DIVA vaccines have emerged as important lines of study and many groups have focused on generating marker vaccines.

CSFV has a genome of about $12.3 \mathrm{~kb}$, which encodes a 3898 amino acid polypeptide from which four structural proteins (C, Erns, E1, and E2) and eight nonstructural proteins (Npro, p7, NS2, NS3, NS4A, NS4B, NS5A, and NS5B) are generated (Meyers et al. 1996). Of the four CSFV structural proteins, the $E 2$ glycoprotein is the main target of neutralizing antibodies generated during CSFV infection and is considered a major antigenic protein in the vaccine market (Ahrens et al. 2000; Bouma et al. 1999; Dewulf et al. 2000). CSFV subunit vaccines have been developed using recombinant E2 proteins expressed in insect cells (Ahrens et al. 2000; Bouma et al. 1999, 2000) and, BAYOVAC ${ }^{\circledR}$ CSF Marker (Advasure ${ }^{\circledR}$, Pfizer, UK) and Porcilis ${ }^{\circledR}$ Pesti (IDEXX CSF marker, IDEXX Europe B.V., the Netherlands) are commercially available in Europe market. Although they were shown to provide protection against CSFV infection, there were reports that they didn't efficiently provide early protection and transplacental transmission (Depner et al. 2001; van Oirschot 2003). In addition to insect cells, other systems using yeast and mammalian cells are also used to produce recombinant E2 proteins (Lin et al. 2012; Hua et al. 2014). However, large-scale manufacturing of these expression system remain expensive. The genotypes of CSFV can be classified into three major groups with several subgroups (Paton et al. 2000; Postel et al.
2013) and it has reported that antibodies specific to one genotype E2 might not provide protection to other CSFV genotypes (Luo et al. 2013). Therefore, in order to effectively protect against the prevalent CSFV in south Korea, it is necessary to develop a vaccine using the E2 protein for this genotype.

There are many bioreactors that produce pharmaceutical proteins. Among other things, plant-based production of recombinant proteins is an attractive platform because plants are easy to grow, produce large amounts of protein, and do not require expensive facilities (Nandi et al. 2016; Sabalza et al. 2014; Lomonossoff and D'Aoust 2016; Rybicki 2017). The E2 protein produced by Arabidopsis thaliana reacts with antibodies against the native E2 protein. In addition, Arabidopsis thaliana-derived E2 antibodies in a mouse can recognize the native E2 protein suggesting that structure of plant-produced E2 is comparable to native E2 protein (Sohn et al. 2018). In addition, transient expression of recombinant E2 protein from the leaves of Nicotiana benthamiana or from the leaves of transgenic $N$. benthamiana lines generates antibodies that can neutralize CSFV in pigs and protect them against subsequent challenge with CSFV (Laughlin et al. 2019; Park et al. 2019).

Immunoglobin $(\mathrm{Ig}) \mathrm{G}$, one of the most abundant proteins in plasma, has a long half-life. The tail ( $\mathrm{Fc}$ region) of these immunoglobulin molecules modulates immune cell activity by interacting with cell surface receptors and with proteins belonging to the complement system (Nimmerjahn and Ravetch 2008). Fusion of the Fc domain with a specific antigenic protein ensures an immune response to that antigen. The main reason for fusing proteins to the $\mathrm{Fc}$ domain is to enhance solubility and the half-life of an antigenic protein (Kontermann 2011; Levin et al. 2015). In addition, the $\mathrm{Fc}$ region enables easy and cost-effective purification of recombinant protein by protein $\mathrm{A}$ chromatography (Carter 2011; Ghose et al. 2006; Huang 2009).

Here, we asked whether a fusion of the CSFV E2 protein and the Fc domain of porcine $\mathrm{IgG}$ could be produced in $N$. benthamiana at low cost. The resulting recombinant protein formed an oligomer rather than a dimer, and injection into mice and pigs generated neutralizing antibodies specific for CSFV. 


\section{Materials and methods}

Plant growth condition

Plants were grown under a $16: 8 \mathrm{~h}$ light:dark cycle in a growth room maintained at $25 \pm 2{ }^{\circ} \mathrm{C}$ and $50 \pm 5 \%$ relative humidity.

\section{Plasmid construction}

We used the pCAMBIA1300 MELCHE2 construct (Park et al. 2019) that contains cellulose binding domain (CBD)-fused E2 as a backbone. The CSFV E2 coding sequence was derived from GenBank (Accession number YP_009508222, amino acid positions 691-1030) and a codon-optimized synthetic gene was purchased (Bioneer Inc. Daejeon, Korea). The pCAMBIA1300 MELCHE2 construct was digested with endonucleases $X m a \mathrm{I}$ and $S a c \mathrm{I}$ to remove the TEV:CBD:HDEL domain. The $\mathrm{pFc} 2$ coding sequence from GenBank (BAM66310.1) was codon-optimized for expression in $N$. benthamiana. Then, it was amplified by polymerase chain reaction (PCR) using the following primers: $X m a \mathrm{I} / \mathrm{pFc} 2-\mathrm{F}$, which contains a $X m a I$ restriction site and $21 \mathrm{nt}$ of the $\mathrm{pFc} 2$ coding sequence, and the HDEL/pFc2-R reverse primer, which contains 12 nt of ER retention signal (HisAsp-Glu-Leu) and $21 \mathrm{nt}$ of the $\mathrm{pFc} 2$ coding sequence. Since the HDEL sequence contains a $S a c$ I restriction site, the PCR product was digested with $\mathrm{XmaI}$ and SacI, and ligated into pCAMBIA1300 MELCH to generate $p C A M B I A 1300:: p m E 2: p F c 2: H D E L$.

Transient expression of chimeric E2 protein

The $p$ CAMBIA1300::pmE2:pFc2:HDEL construct was introduced into A. tumefaciens strain LBA4404 by electroporation. Separate cultures of Agrobacterium harbouring $p C A M B I A 1300:: p m E 2: p F c 2: H-$ $D E L$ and Agrobacterium harbouring p38, silencing repressor, were grown overnight in YEB liquid medium. Agrobacterium cells were collected by centrifugation at $3500 \times g$ for $20 \mathrm{~min}$ and resuspended in infiltration buffer $\left(10 \mathrm{mM}\right.$ MES, $10 \mathrm{mM} \mathrm{MgSO}_{4}$, $100 \mu \mathrm{M}$ acetosyringone, $\mathrm{pH}$ 5.6) to reach $\mathrm{OD}_{600}$ of 1.0 and mixed each in a 1:1 ratio $(\mathrm{v} / \mathrm{v})$. Leaf tissues of 5 to 7-week-old $N$. benthamiana plants were co-infiltrated with the Agrobacterium-mixture of suspension cells.
Plants were returned to the greenhouse and grown for a further 4 DPI (day post infiltration). For expression analysis of the fusion protein, fresh leaf tissues were ground under liquid nitrogen to a fine powder in protein extraction buffer $(50 \mathrm{mM}$ Tris- $\mathrm{HCl}, \mathrm{pH} 7.5$, $150 \mathrm{mM} \mathrm{NaCl}, 0.1 \%$ [v/v] Triton X-100). Total soluble proteins (TSP) were extracted from the ground tissue samples. After filtering with Miracloth (EMD Millipore Corp., Billerica MA, USA; Cat. No:475855$1 \mathrm{R})$, lysates were clarified by centrifugation $(13,000 \times g)$ for $20 \mathrm{~min}$ and Soluble and insoluble fractions were collected.

Generation of transgenic plants

The $p C A M B I A 1300:: p m E 2: p F c 2: H D E L$ construct was introduced into A. tumefaciens strain LBA4404 by electroporation. For plant tissue culture, N. benthamiana leaves were fragmented into $0.5 \mathrm{~cm} \times 0.5$ $\mathrm{cm}$ pieces, and incubated for $10 \mathrm{~min}$ with A. tumefaciens transformed with pCMABIA1300::E2:pFc2 in Murashige and Skoog (MS) liquid medium containing $2.0 \mathrm{mg} / \mathrm{l}$ a-naphthaleneacetic acid (NAA) and $0.5 \mathrm{mg} / \mathrm{l}$ 6-benzylaminopurin (6-BAP). Next, the culture medium was removed, and the leaf fragments were placed upside down (i.e., basal side up) on solid MS medium (which had the same composition as the liquid medium) and incubated for 3 days. After washing with MS liquid medium, the leaves were placed upside down on MS solid medium containing $1.0 \mathrm{mg} / \mathrm{l} \mathrm{NAA}$, $0.5 \mathrm{mg} / \mathrm{l}$ 6-BAP, $200 \mathrm{mg} / \mathrm{l} \mathrm{kanamycin}$, and $250 \mathrm{mg} / \mathrm{l}$ cefotaxime, and incubated in the dark for 7-10 days. Next, leaves were exposed to light, leading to growth of shoots and roots. The plants were transferred to soil and expression of pmE2:pFc2 was analyzed by western blot analysis of leaf extracts prepared by homogenizing leaves in extraction buffer, followed by centrifugation to yield a supernatant. After harvesting seeds, T3 generation transgenic plants were selected in the presence of hygromycin at a segregation ratio of $3: 1$.

Protein purification and western blot analysis

Briefly, $0.5 \mathrm{~kg}$ (fresh weight) leaves from transgenic plants were harvested and homogenized in a blender $(32,000 \mathrm{rpm})$ in the presence of $1 \mathrm{~L}$ protein extraction buffer (50 mM sodium phosphate buffer, $\mathrm{pH} 8.0,300$ $\mathrm{mM} \mathrm{NaCl}, 100 \mathrm{mM}$ glycine, $0.5 \%$ Triton $\mathrm{X}-100)$. To 
remove debris, extracts were centrifuged for $40 \mathrm{~min}$ at $20,000 \times g$ and supernatants were filtered through Miracloth. Extracts were incubated for $1 \mathrm{~h}$ with 20 $\mathrm{mL}$ Protein A Agarose Resin (Amicogen, Jinju, Republic of Korea; Cat. No: 1010200). Next, the extract and resins were loaded onto a column at a flow rate of $20 \mathrm{~mL} / \mathrm{min}$ and washed three times with 200 $\mathrm{mL}$ washing buffer $(50 \mathrm{mM}$ sodium phosphate buffer, $\mathrm{pH}$ 8.0, $300 \mathrm{mM} \mathrm{NaCl}$ ). Recombinant E2 proteins were eluted using elution buffer $(100 \mathrm{mM}$ sodium citrate, $\mathrm{pH} 3.0,300 \mathrm{mM} \mathrm{NaCl}$ ), followed by addition of $3 \mathrm{M}$ Tris-Cl to obtain a $\mathrm{pH}$ of 7.2. Each fraction was collected and subjected to western blot analysis. Briefly, proteins were run on $10 \%$ SDS-PAGE gels, transferred to PVDF (Polyvinylidene difluoride) membranes (Merck Milipore Ltd., Tullagreen Carrigtwohill; Cat. No:IPVH00010), and incubated with an antibody specific for HRP-conjugated swine $\mathrm{IgG}$ (Bethyl Laboratoris, Montgomery, USA; Cat. No: A100-250P) or CSFV (Median, Chuncheon, Republic of Korea; Cat. No.9011) coupled with anti-mouse IgG HRP-conjugated (Bethyl, Montgomery, USA). Immunoblotting bands were visualized using SUPEX Solution kit (Neutronex, Goryeong, Republic of Korea; Cat. No. NXECL-2011) as a substrate and images were obtained with a Chemiluminescence Imaging system (Vilber, FRANCE). Bands were visualized with Coomassie Brilliant Blue R-250 (Biosolution, Suwon, South Korea; Cat. No: BC006).

For concentration of purified protein, eluted fraction was subjected to centrifuge at $3000 \times g$ using Ultrafiltration unit (Sartorius, United Kingdom, Cat. No. VS6021).

Size exclusion chromatography and native-PAGE

Size exclusion chromatography was performed using the ÄKTA Prime chromatography system and a HiLoadTM 16/60 Superdex 200 pg (GE Healthcare, Madison, WI, United States) column. The column was washed and equilibrated with $120 \mathrm{ml}$ buffer $(50 \mathrm{mM}$ Tris-Cl, pH 7.2, $300 \mathrm{mM} \mathrm{NaCl}, 0.5 \mathrm{mM}$ EDTA) prior to loading of pmE2 proteins at a flow rate of $1.5 \mathrm{ml} /$ min. Absorbance at $280 \mathrm{~nm}$ was monitored, and fractions were collected and subjected to $8 \%$ polyacrylamide gel electrophoresis (PAGE) without sodium dodecyl sulfate (SDS) under non-reducing conditions. Blue-Dextran (2000 kD), Alcohol dehydrogenase (150 kD), Bovine Serum Albumin (66 kD),
Carbonic Anhydrase (29 kD), and Cytochrom C (12.4 $\mathrm{kD})$ for Size exclusion chromatography and Thyroglobulin (669 kD), Ferritin (440 kD), Catalase (232 $\mathrm{kD})$, Lactate dehydrogenase (140 kD), and BSA (67 $\mathrm{kD})$ for PAGE were used as protein molecular-weight standards. The gels were stained with Coomassie Brilliant Blue R-250.

Immunization of mice with pmE2:pFc2 and ELISA

Mice (C57BL/6J, male, 6 weeks old) were used for immunization. All animals were handled in accordance with the guidelines and protocols approved by the Pohang University of Science and Technology (POSTECH) Animal Care and Use Committee. Mice were kept isolated for 1 week prior to the experiments to ensure that they were healthy. For single dose immunization, mice received a subcutaneous injection of $1 \mu \mathrm{g}$ pmE2:pFc2 fusion protein in Freund's complete adjuvant (Sigma, Cat. No. F5881) (Yoshikai et al. 1990). Bloods were collected from Retro-Orbital plexus weekly and tested in an ELISA. For double immunizations, mice received $1 \mu \mathrm{g}$ pmE2:pFc2 fusion protein in Freund's complete adjuvant, followed 2 weeks later by a second dose in Freund's incomplete adjuvant (Sigma, Cat. No. F5506). Blood samples were collected prior to the primary injection and then weekly (weeks 3 to 8 ) after the first injection.

Blood samples were centrifuged for $15 \mathrm{~min}$ at $3000 \times g$ to obtain sera and the resulting sera were further analyzed by a commercially available ELISA kit (A VDPro ${ }^{\circledR}$ CSFV AB ELISA kit; Median, Chuncheon, Republic of Korea, Cat. No. ES-CSF01) to detect anti-pmE2:pFc2 antibodies. Briefly, the 96-well microplate coated with CSFV E2 antigen and all kit reagents were placed on a bench and allowed to reach room temperature for at least $30 \mathrm{~min}$ before use. Next, serum samples (diluted 1:10,000) were added to the plates in duplicate. Positive and negative controls were diluted 20 -fold. Samples $(100 \mu \mathrm{L})$ were added to the plate and incubated at $37^{\circ} \mathrm{C}$ for $1 \mathrm{~h}$. Next, $100 \mu \mathrm{L}$ horseradish peroxidase (HRP)-conjugated anti-mouse $\operatorname{IgG}$ (1:5000 dilution) was added to each well for $1 \mathrm{~h}$ at $37^{\circ} \mathrm{C}$. After rinsing with wash buffer, $100 \mu \mathrm{L}$ ABTS substrate was added to each well, followed by incubation for $10 \mathrm{~min}$ at room temperature. The reaction was stopped by addition of $100 \mu \mathrm{L}$ Stop Solution. Absorbance at $405 \mathrm{~nm}$ was read in an ELISA 
Reader (Thermo Fisher Scientific, MULTISKAN FC, Cat. no. N07710). Sample to positive ratio (S/P value) was calculated by (OD sample - OD negative control mean $)$ / OD positive control mean. Test samples with an $\mathrm{S} / \mathrm{P}$ ratio $\geq 0.14$ are positive; those with an $\mathrm{S} / \mathrm{P}$ ratio $<$ 0.14 are negative. The experiments were repeated three times and presented a representative result.

Vaccination of pigs with pmE2:pFc2

All experiments involving pigs complied with the current laws of South Korea. Animal care and treatment were conducted in accordance with guidelines established by the Animal and Plant Quarantine Agency Animal Care and Use Committee (QIAACUC). The study was approved by QIA-ACUC (permit number 2017-369).

Six piglets (aged 40 days) were allotted randomly to a control group $(n=2)$ or a vaccinated group $(n=4)$. The vaccine was prepared by simple hand mixing of $150 \mu \mathrm{g}$ pmE2:pFc2 with an oil-in-water emulsion adjuvant (ISA 15A VG; SEPPIC MONTANIDE ${ }^{\text {TM }}$, Paris, France). The final volume was $1 \mathrm{ml}$, which was injected intramuscularly. Piglets from the control group were injected with the same volume of PBS. Pigs received a booster vaccination 20 days after the primary vaccination (the same vaccine formulation was used). Blood samples were collected on Day 0 , immediately before the second vaccination, and at 20 , 60,90 , and 110 days after the second vaccination; neutralizing antibody responses were then examined.

Serum anti-CSFV neutralizing antibody assay

Sera were tested for the presence of anti-CSFV neutralizing antibodies using a neutralizing peroxidase linked assay in accordance with the standards set out in the manual of the OIE (OIE 2013). In brief, sera were serially diluted to twofold (1:2 to $1: 2048)$ in serum-free MEM media containing $1 \mu \mathrm{g} / \mathrm{ml}$ trypsin and $50 \mu \mathrm{l}$ of aliquots were added in a 96-well plate. An equal volume of $200 \mathrm{TCID}_{50} / \mathrm{mL}$ of CSFV LOM strain was added to each well and incubated for $1 \mathrm{~h}$ at $37{ }^{\circ} \mathrm{C}$ in $5 \% \mathrm{CO}_{2} .100 \mu \mathrm{l}$ of $\mathrm{CPK}$ (cloned porcine kidney) cells $\left(1 \times 10^{6} / \mathrm{ml}\right)$ was added to each well and incubated for 3 days at $37{ }^{\circ} \mathrm{C}$ in $5 \% \mathrm{CO}_{2}$. The cells were fixed with $100 \mu \mathrm{l}$ of pre-chilled $80 \%$ acetone for $7 \mathrm{~min}$ at $-20{ }^{\circ} \mathrm{C}$. After drying a plate at $37{ }^{\circ} \mathrm{C}$, commercial anti-LOM antibody (Median Diagnostics;
Cat. No. 9011) (100 $\mu$ l of 200-fold dilution) was added and incubated for $1 \mathrm{~h}$ at $37{ }^{\circ} \mathrm{C}$. After rinsing out the plate with PBS three times, biotinylated goat antimouse IgG antibody (Vector Lab; Cat. No. BA-9200) (100 $\mu \mathrm{l}$ of 200 -fold dilution) was added and incubated for $1 \mathrm{~h}$ at $37^{\circ} \mathrm{C}$. After washing three times with PBS, VECTASTAIN ABC-HRP Kit (Vector Lab; Cat. No. PK-4000) was added according to the manufacturer's instructions and incubated for $1 \mathrm{~h}$ at $37{ }^{\circ} \mathrm{C}$. After washing three times with PBS, ImmPACT DAB Peroxidase (HRP) Substrate (Vector Lab; Cat. No. SK-4100) was added according to the manufacturer's instructions. Neutralizing antibody titers in serum samples were expressed as the reciprocal of the highest dilution that yielded $50 \%$ neutralization.

\section{Results}

Generation of the pmE2:pFc2 fusion construct and protein expression in $N$. benthamiana

To investigate whether the recombinant pmE2:pFc2 (porcine $\mathrm{Fc}$ fragment) fusion was effective as a vaccine, we first constructed a DNA construct for expression in plants. The E2 protein was expressed at high levels after targeting to the endoplasmic reticulum (ER). This was achieved by adding an upstream BiP leader sequence and a downstream HDEL ER retention signal. In addition, we inserted 17 nucleotides into the $5^{\prime}$ UTR region and an Arabidopsis HSP terminator into the $3^{\prime}$ UTR region to increase expression (Kim et al. 2014; Nagaya et al. 2010). Previously, we tested three different $\mathrm{Fc}$ domains $(\mathrm{pFc} 1, \mathrm{pFc} 2$, and $\mathrm{pFc} 3$ ) from Sus scrofa and found out that $\mathrm{pFc} 2$ showed strongest expression in $N$. benthamiana (data not shown). Therefore, we fused the $\mathrm{pFc} 2$ domain downstream of the pmE2 coding sequence to generate the pmE2:pFc2 fusion construct (Fig. 1a). The pFc2:pmE2 fusion protein generated by transient expression in N. benthamiana leaves using Agrobacterium tumefaciens was detected in the soluble fraction, indicating that $\mathrm{pFc} 2$ increases the solubility of the antigenic protein (Fig. 1b, c). When we looked more closely, we noted a strong band at around $70 \mathrm{kD}$. The expected size of the $\mathrm{E} 2$ recombinant protein is $64 \mathrm{kD}$; therefore, the strong band appeared to be larger than expected. We assume that this is due to $\mathrm{N}$-glycosylation since $\mathrm{E} 2$ protein has putative $7 \mathrm{~N}$-glycosylation 
A

- 1300::pmE2:pFc2

$35 \mathrm{~S}>\mathrm{UTR}:: \mathrm{L} \quad \mathrm{pmE2}(\mathrm{GP} 55)-\mathrm{pFc} 2, \mathrm{HDEL}-\mathrm{Hsp}-\mathrm{T}$

\section{B}

\section{$\begin{array}{lllll}M & \mathrm{~T} & \mathrm{~S} & \mathrm{P} & \mathrm{WT}\end{array}$}

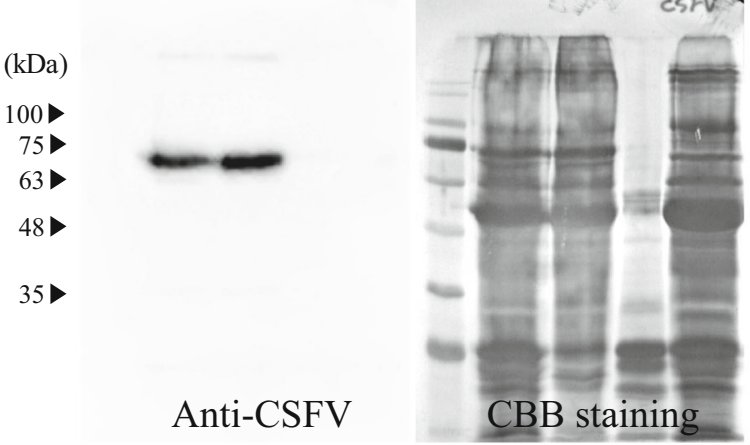

D

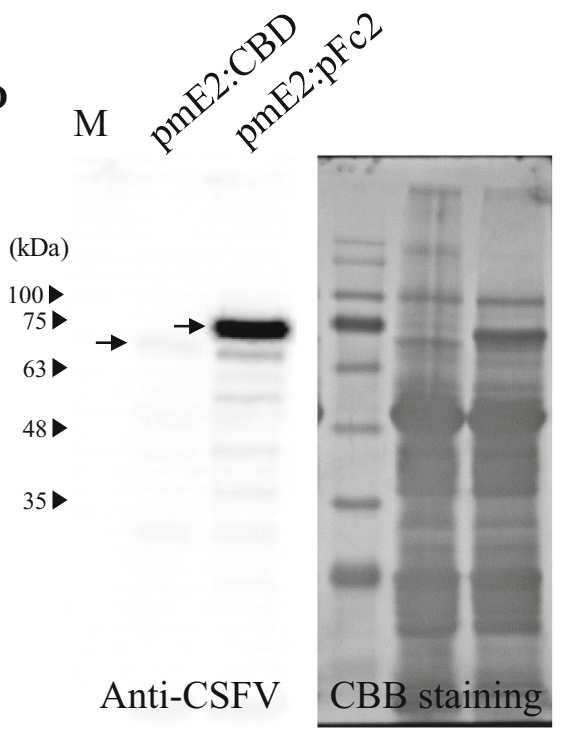

Fig. 1 Construction of 1300::pmE2:pFc2:HDEL and expression in $N$. benthamiana. $\boldsymbol{a}$ Schematic showing the 1300::pmE2:pFc2:HDEL construct. 35S, double cauliflower mosaic virus $35 \mathrm{~S}$ promoter; UTR::L, $5^{\prime}$ untranslated region and BiP endoplasmic reticulum (ER)-leader sequence; pmE2, transmembrane domain-deleted classical swine fever virus envelope glycoprotein $\mathrm{E} 2$; pFc2, IgG heavy chain constant region from Sus scrofa; HDEL, ER retention signal; Hsp-T, Arabidopsis HSP terminator. b and $\mathbf{c}$ Western blot analysis of expression and solubility of the recombinant protein. Total protein was prepared from leaves and separated to soluble and

sites (Laughlin et al. 2019). Consistent with this, previous studies reported that CBD-fused E2 recombinant proteins have several $\mathrm{N}$-glycosylation sites and

\section{C $\begin{array}{lllll}M & \mathrm{~T} & \mathrm{~S} & \mathrm{P} & \mathrm{WT}\end{array}$}

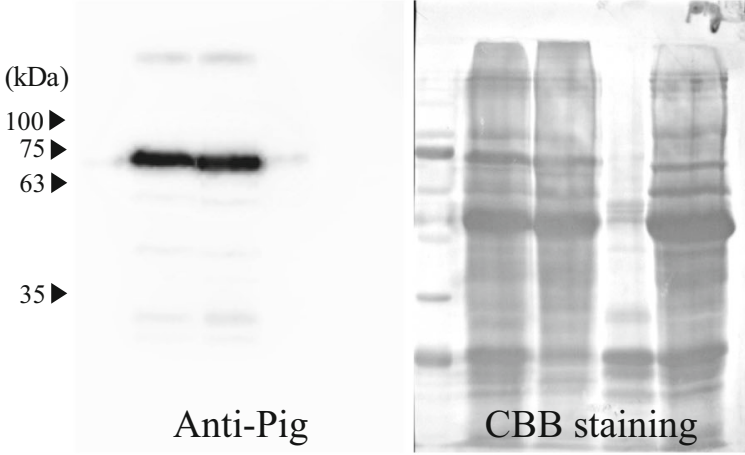

insoluble fractions by centrifugation at $20,000 \times g$ for $15 \mathrm{~min}$. Each fraction was subjected to western blotting with an antiCSFV antibody and an anti-Pig antibody. The membrane was stained with Coomassie Brilliant Blue. $M$ protein markers (molecular weights in $\mathrm{kD}$ are shown on the left), $T$ plant total extract, $S$ soluble fraction, $P$ pellet fraction, $W T$ wild-type plants. d Comparison of expression levels of CBD- or $\mathrm{pFc} 2$ fused pmE2. Total extracts were subjected to western blot analysis using anti-CSFV antibody. The arrows indicate recombinant pmE2 proteins

are larger than expected when expressed in plants (Park et al. 2019; Sohn et al. 2018). In addition, the $\mathrm{pFc} 2$ domain contains one N-glycosylation site 
suggesting that the larger size is caused by N-glycosylation of both pmE2 and $\mathrm{pFc} 2$. To test expressional superiority of the $\mathrm{pFc} 2$ fusion, we compared expression levels of pmE2:pFc2 with cellulose-binding domain (CBD):pmE2 by western blotting (Fig. 1d). CBD is derived from Clostridium thermocellum and binds to cellulose; therefore, it can be used as a tag for protein purification (Park et al. 2019). As a result, the amount of pmE2:pFc2 was much higher than that of CBD-fused pmE2 when total extracts were prepared from identical fresh weight of leaves. There results suggested that $\mathrm{pFc} 2$ fusion increases the expression level of pmE2 protein as well as solubility.

Generation of pmE2:pFc2 in transgenic $N$.

\section{benthamiana}

Next, we tried to generate pmE2:pFc2 in transgenic plants to ensure more consistent expression. Similar to transient expression, we performed tissue culture using A. tumepaciens after introduction of pCAMBIA 1300::E2:pFc2. We obtained dozens of T0 lines. Western blot analysis revealed that several lines expressed high amounts of recombinant protein; therefore, we selected homogenous lines from T2 plants. To select the most strongly expressed line among four T2 generation plants, we performed further western blot analysis and finally obtained total extracts from two or three lines (Fig. 2a). Expression of recombinant protein was strongest in transgenic line 42. When we compared this transgenic plant with a wild-type plant, we found no significant difference in biomass. Therefore, we used this line to generate recombinant protein (Fig. 2b).

\section{Purification of recombinant pmE2:pFc2}

To purify pmE2:pFc2 recombinant protein, total protein extracts were prepared from the leaves of the transgenic plant using protein extraction buffer. The pmE2:pFc2 fusion was purified by affinity chromatography on protein A beads. All fractions including total, flow-through contained unbound E2, wash-off and elution were monitored by western blot analysis (Fig. 3a). Compared with the total protein extract, the flow-through fractions contained around 10\% unbound $\mathrm{E} 2: \mathrm{pFc} 2$. In addition, the first-wash fraction exhibited only faint bands, while the second- and third-wash fractions contained very little E2, indicating tight binding of $\mathrm{E} 2 \mathrm{pFc} 2$ to protein $\mathrm{A}$ beads. Almost all the E2 protein was present in the eluted fraction; very little remained on the beads after elution, indicating that the elution buffer stripped the beads effectively.

Producing a vaccine from a recombinant protein requires a concentration step to generate a high concentration of antigenic protein in a small volume. Therefore, purified proteins must be concentrated, a process that can result in loss of protein due to aggregation. When we concentrated the eluted fraction by centrifugal filtration, it was enriched without aggregation. Next, the proteins were loaded onto SDS-PAGE gels along with known concentrations of bovine serum albumin (BSA) (Fig. 3b). We estimated that the amount of pmE2 protein was about $1.135 \mu \mathrm{g} /$ $\mu \mathrm{l}$, and that $302 \mathrm{mg}$ pmE2 protein could be produced from $1 \mathrm{~kg}$ plant leaves.

\section{Characterization of pmE2:pFc2}

Previous reports suggest that the CSFV E2 protein forms a dimer (Lin et al. 2009; Hua et al. 2014; Risatti et al. 2007; Thiel et al. 1991). However, we showed previously that the E2 protein fused to a CBD was expressed in plants as an oligomer (Park et al. 2019). Moreover, $\mathrm{pFc} 2$ forms dimers via the tail part of the antibody (Janeway et al. 2001). Thus, we performed SDS-PAGE under reducing and non-reducing conditions to investigate whether purified pmE2 protein forms dimers or oligomers when expressed in plants. We observed a band that was much larger than that expected for the protein only under non-reducing conditions (Fig. 4a). This indicates that the recombinant protein was multimeric. To confirm this, we subjected the purified protein to size exclusion chromatography (Fig. 4b). We observed a small peak at 54 $\mathrm{ml}$ and a major peak at $60 \mathrm{ml}$; no peak was observed in the fraction corresponding to a monomer $(78 \mathrm{ml})$. The major peak was slightly larger than the peak corresponding to $150 \mathrm{kDa}(64.18 \mathrm{ml})$. To confirm that these peaks were pmE2, each fraction from each peak was analyzed by native-PAGE; bands were observed at sizes corresponding to a tetramer or a pentamer (Fig. 4c). By contrast, no protein was in the fraction corresponding to the peak at $54 \mathrm{ml}$ (data not shown). This result is consistent with data derived from CBD- 


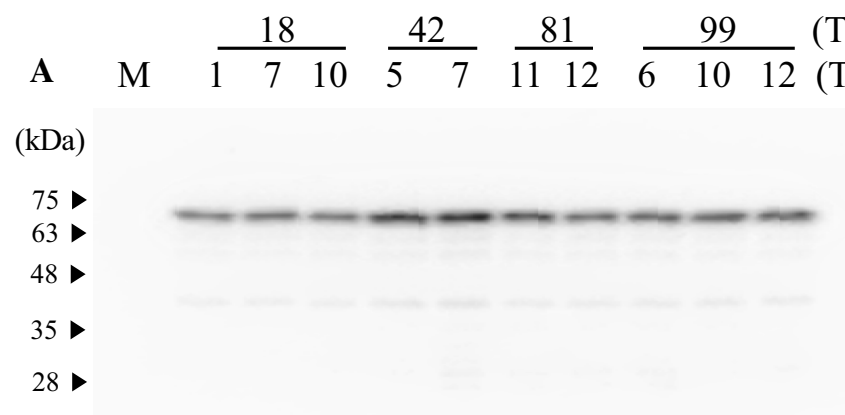

B

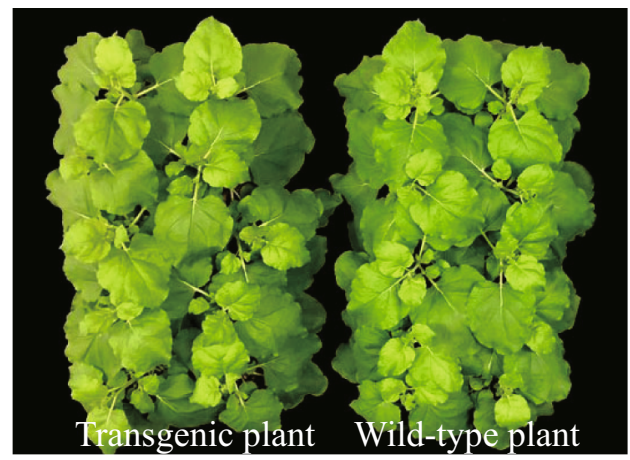

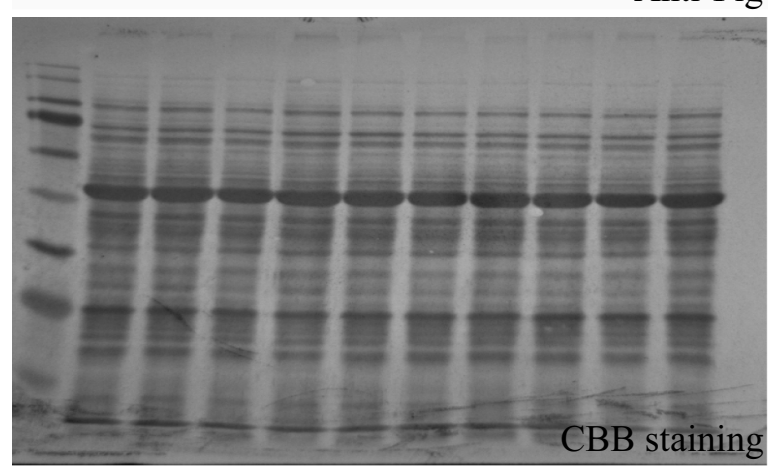

Fig. 2 Selection of 1300::pmE2:pFc2:HDEL-expressing transgenic plants. a Western blot analysis of 1300::pmE2:pFc2:HDEL expression in transgenic plants (T2 generation). The same amount of total protein extract was prepared from two or three independent lines of four T2 generation transgenic plants and subjected to immunoblotting with an anti-Pig antibody. The blot was visualized by staining with Coomassie Brilliant Blue in

fused pmE2. Therefore, we believe that these characteristics are due to pmE2 itself, rather than to the tags, when expressed in plants.

\section{Immunogenicity of pmE2:pFc2 in mice}

Prior to testing the vaccine in pigs, we used pmE2:pFc2 to immunize mice to assess whether recombinant pmE2 protein produced from $N$. benthamiana acts as a vaccine. Mice (C57BL/6J, male, 6 weeks old) received a subcutaneous injection of $1 \mu \mathrm{g}$ pmE2:pFc2 in complete Freund's adjuvant or the same volume of PBS (as a control). After one-dose injection, serum samples were collected on a weekly basis and antibody levels were tested in an ELISA (Fig. 5). Anti-CSFV antibody levels in all mice increased gradually, peaking at 4-5 weeks. These levels were order to verify the clarity of total protein extraction processes. $\mathrm{M}$, protein markers; upper numbers indicate transgenic lines at T0; bottom numbers indicate transgenic lines at T2. b Phenotypical comparison of wild-type and transgenic plants. Plants were grown side by side from the same germination stage and the morphology was compared at 37 days-of-age

maintained or decreased slightly until week 8 indicating that the chimeric protein produced from plant acts as an antigen. In addition, we used mouse serum (week 8 ) to test for neutralizing antibodies (Table 1) in order to investigate whether the antibody against recombinant pmE2 can provide protection against CSFV. Most sera had neutralizing antibody titers of $2^{7}-2^{9}$, although slight variations were observed. This level of neutralizing antibodies suggests that the fusion protein has great potential as a vaccine.

Verification of CSFV antibody-mediated neutralization in serum from pigs immunized with $\mathrm{pFc} 2$ :pmE2

Finally, piglets were injected with $150 \mu \mathrm{g}$ pmE2:pFc2 in ISA $15 \mathrm{~A} \mathrm{VG}$, and neutralizing antibody responses were verified by testing serum in a virus neutralization 
A
$\begin{array}{llllllll}\text { M } & \text { T } & \text { FT } & \text { W1 } & \text { W2 } & \text { W3 } & \text { E } & \text { EB }\end{array}$
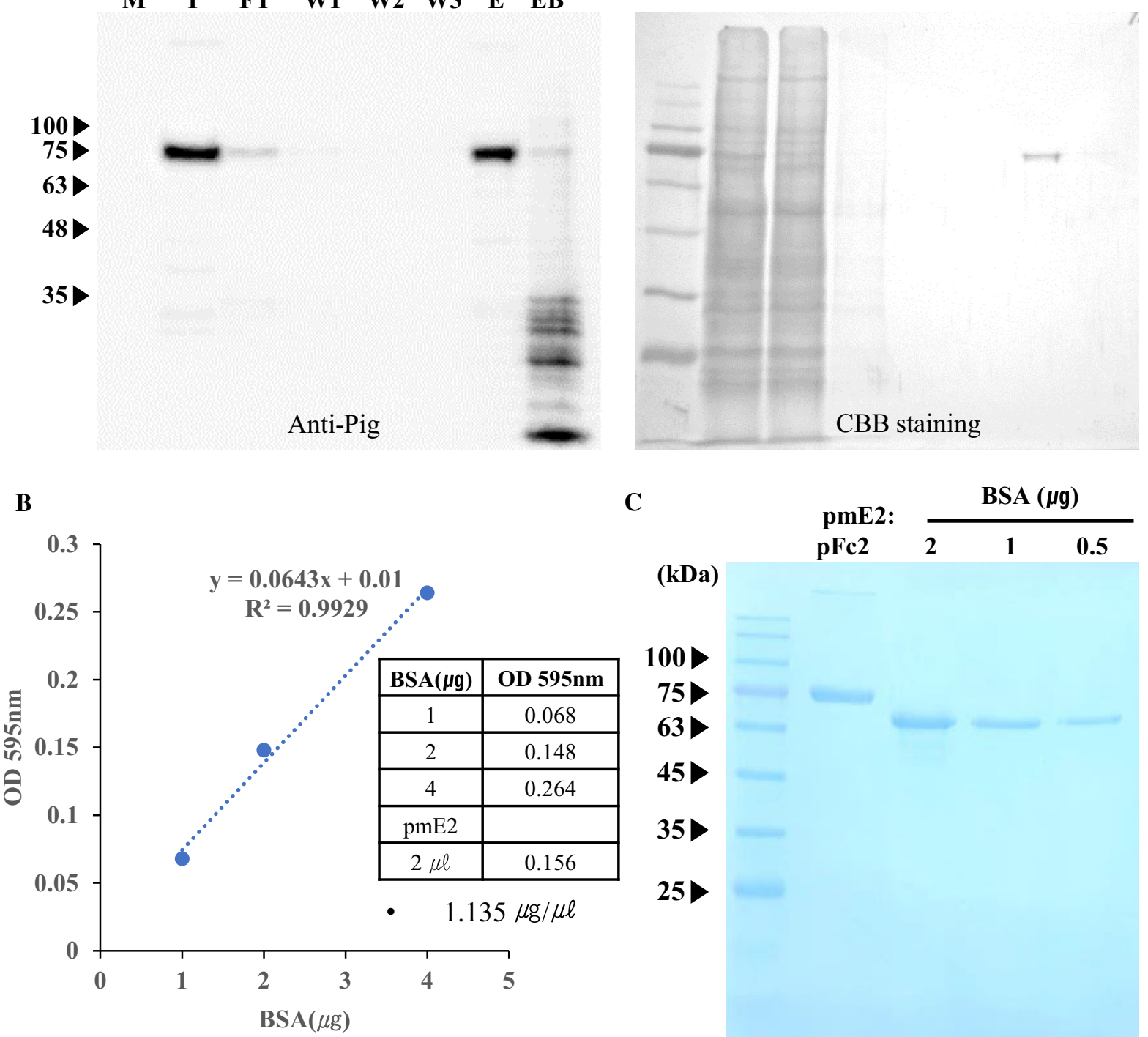

C

pmE2: $\quad$ BSA $(\mu \mathrm{g})$
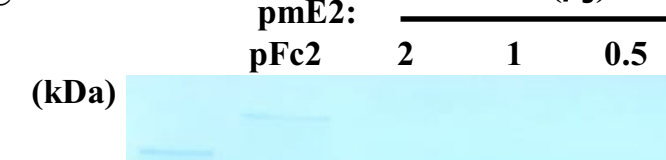

100

75

63

45

35

25

Fig. 3 Purification and quantitative analysis of the pmE2 fusion protein. a Purification of the $\mathrm{pmE2}$ : $\mathrm{pFc} 2$ recombinant protein by protein A chromatography. Total extracts were prepared from transgenic plant leaves by incubation in extraction buffer, followed by centrifugation. Samples were loaded onto a column containing protein A resin. After binding, resin-bound recombinant proteins were washed three times and then eluted in elution buffer. Each fraction was separated by SDS-PAGE and subjected to western blot analysis with an antibody specific for anti-pig IgG (whole). $T$ total fraction, FT flow-through, W1-3

test (Table 2). Four of six pigs (aged 40 days) were vaccinated with $150 \mu \mathrm{g}$ pmE2:pFc2 and then boosted 20 days later with the same vaccine formulation. The other two pigs were injected with the same volume of wash-off fractions, $E$ elution fraction, $E B$ post-elution resin content. b Quantification of purified pmE2:pFc2. Purified protein from a was concentrated by centrifugal filtration, and subjected to perform Bradford assay. Linear regression was generated by using 1,2 and $4 \mu \mathrm{g}$ of bovine serum albumin (BSA) and $2 \mu \mathrm{g}$ of pmE2:pFc2 was used for quantification. c Quantification of pmE2:pF2 by SDS-PAGE. $2 \mu \mathrm{g}$ of pmE2:pFc2 and simultaneously, $0.5,1$, and $2 \mu \mathrm{g}$ bovine serum albumin (BSA) was run for comparison. The gel was visualized by Coomassie Brilliant Blue staining and band intensities were compared

PBS (control). Serum was obtained from each pig at 20,60,90, and 110 days post-second vaccination and neutralizing antibody titers were measured. Although some neutralizing antibodies were detected as early as 


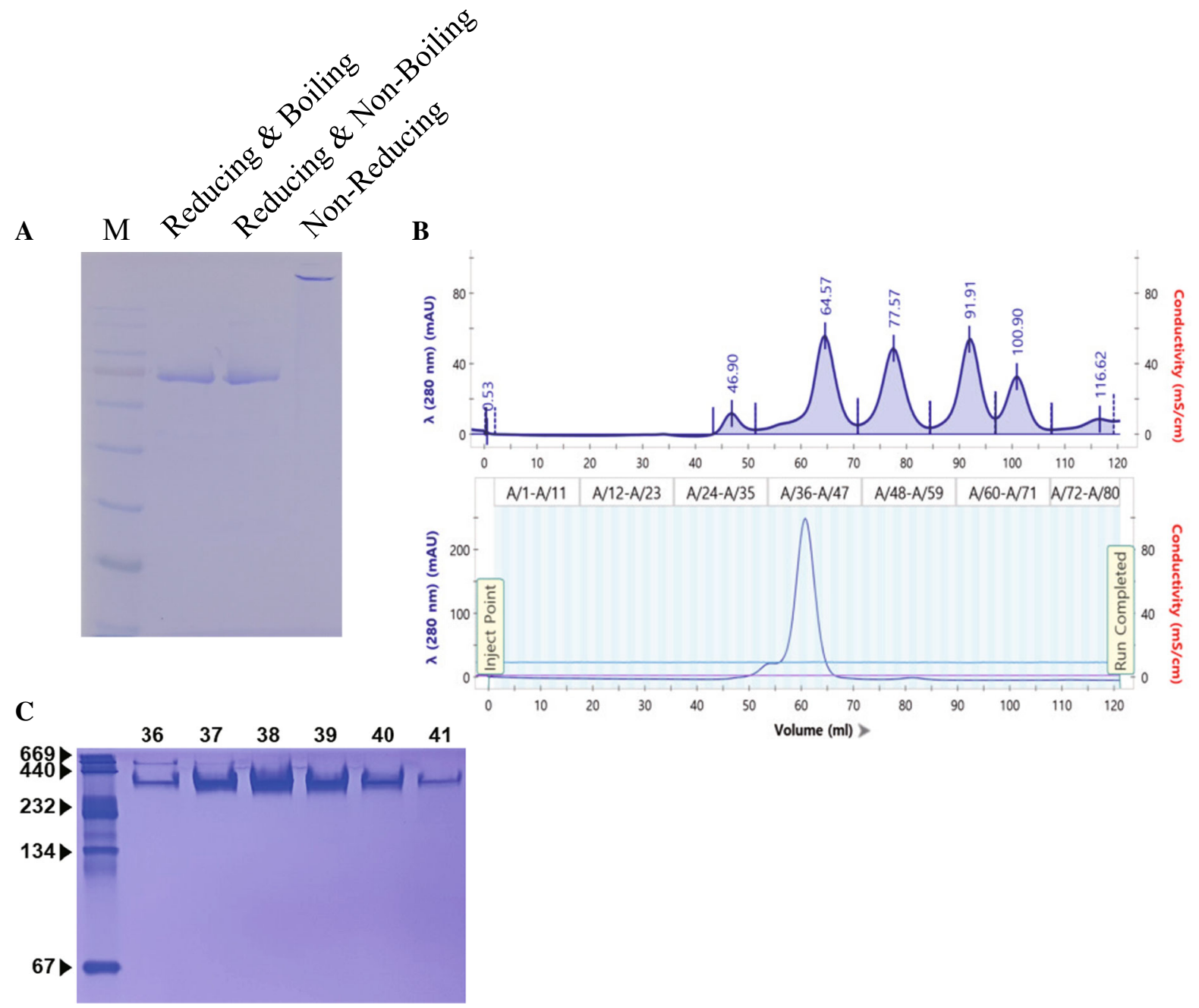

Fig. 4 Characterization of pmE2:pFc2 recombinant Status of pmE2:pFc2 under different conditions. Purified protein was treated with $\beta$-mercaptoethanol and/or boiling, and then separated by SDS-PAGE. The gel was visualized by Coomassie Brilliant Blue staining. b Size exclusion chromatography of pmE2:pFc2. Purified recombinant proteins were injected onto a size exclusion column and separated (bottom panel). Blue-

20 days after the primary vaccination, a marked increase in titer was observed at 20 days post-booster vaccination. The high neutralizing antibody titers were maintained at values $>6(\log 2)$ for 170 days, although they fell gradually after reaching a peak at aged 80 days. Thus, pmE2:pFc2 generated neutralizing antibodies specific for CSFV in the natural host.
Dextran (2000 kD), Alcohol dehydrogenase (150 kD), Bovine Serum Albumin (66 kD), Carbonic Anhydrase (29 kD), and Cytochrom C (12.4 kD) were used as protein molecular-weight standards (upper panel). c Native-PAGE analysis of recombinant proteins eluted from the column. The fraction corresponding to the major peak from $\mathbf{b}$ was separated on $8 \%$ Native-PAGE gels and visualized by CBB staining

\section{Discussion}

Most CSFV vaccines in use today in CSF-endemic areas, including Asia, are modified live vaccines (MLV); although MLVs provide good protection against CSFV infection, it is difficult to distinguish between infected and vaccinated pigs (Blome et al. 2006; Deng et al. 2005; van Oirschot 2003). Therefore, it is difficult to prove that the area is free from this disease, which constrains import and export of pigs. 
Fig. 5 Immunogenicity of pmE2:pFc2 in mice. PmE2:pFc2 fusion protein $(1 \mu \mathrm{g})$ combined with Freund's complete adjuvant was injected into mice. Sera were collected every week post-vaccination and subjected to ELISA. The negative control comprised the volume of PBS. Signal intensity was measured at A405

Table 1 Single- and double-dose vaccination and classical swine fever virus (CSFV) neutralizingantibody titers from mouse serum

$V N A$ virus neutralizing antibody, $C S F V$ neutralizing antibody titers were measured as described in the Materials and methods section

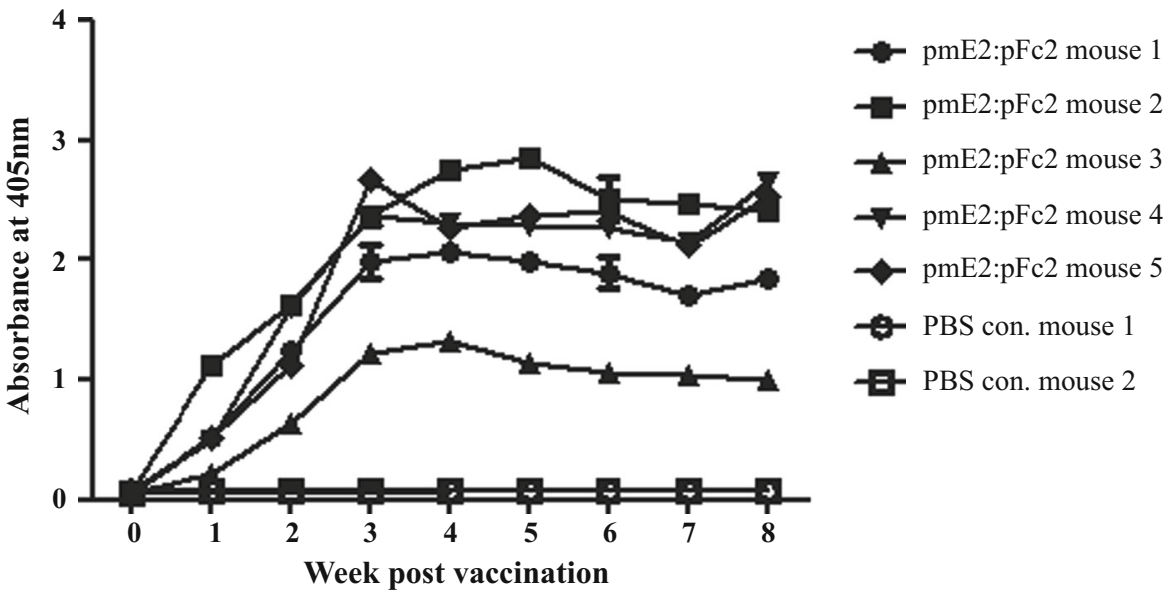

\begin{tabular}{lllr}
\hline Vaccination & Antigen & Mouse ID\# & VNA titer \\
\hline Single-dose vaccination & pmE2:pFc2 & 1 & 128 \\
& & 2 & 256 \\
& & 3 & 32 \\
& & 4 & 256 \\
pouble-dose vaccination & & 5 & 512 \\
& & 1 & 256 \\
& & 2 & 256 \\
& & 3 & 64 \\
Back titers & 4 & 128 \\
Negative control & 5 & 64 \\
Positive control & & 177 \\
\hline
\end{tabular}

To solve these problems, subunit marker vaccines are being developed. Many studies are examining the efficacy of vaccines based on the CSFV E2 glycoprotein; indeed, some products have come to market: BAYOVAC ${ }^{\circledR}$ CSF Marker (Advasure ${ }^{\circledR}$, Pfizer, UK) and Porcilis ${ }^{\circledR}$ Pesti (IDEXX CSF marker, IDEXX Europe B.V., the Netherlands). The two viral glycoproteins $\mathrm{E} 2$ and $\mathrm{E}^{\mathrm{rns}}$ are necessary for viral attachment to host cells; of these, E2 is the major envelop glycoprotein that induces production of anti-CSFV neutralizing antibodies (König et al. 1995; Weiland et al. 1990). Previously, we demonstrated that an E2 glycoprotein fused with a CBD was immunogenic in pigs and confirmed that it provided efficient protection against CSFV challenge (Park et al. 2019). Here, we intended to use the recombinant protein $\mathrm{Fc}$ domain from pig $\operatorname{IgG}$ as an alternative to the CBD and evaluate its efficacy in animals. An ideal vaccine should not only be efficient and safe, but also affordable for endusers. Simple and successful expression of large amounts of recombinant protein with high immunogenicity is the key to cost-effectiveness. This is why we chose the porcine IgG Fc domain as the fusion partner. The Fc domain improved solubility and increased expression of E2 when expressed in plants. In addition, the Fc domain makes isolation of recombinant proteins by protein A affinity chromatography both easy and cheap. Although protein A resin is not cheap, appropriate use and management through a cleaning-in-place protocol means that hundreds of purification cycles can be performed without disassembly of the equipment, resulting in significant 
Table 2 CSFV-neutralizing antibody responses in pmE2:pFc2 vaccinated piglets

\begin{tabular}{|c|c|c|c|c|c|c|c|}
\hline & $\begin{array}{l}\text { Age } \\
\text { Piglet } \\
\text { ID\# }\end{array}$ & $\begin{array}{l}40 \text {-day } \\
1 \mathrm{st} \\
\text { injection }\end{array}$ & $\begin{array}{l}\text { 60-day } \\
\text { 2nd } \\
\text { injection }\end{array}$ & $\begin{array}{l}80 \text {-day } \\
20 \text { days post- } \\
\text { boosting }\end{array}$ & $\begin{array}{l}110 \text {-day } \\
60 \text { days post- } \\
\text { boosting }\end{array}$ & $\begin{array}{l}150 \text {-day } \\
90 \text { days post- } \\
\text { boosting }\end{array}$ & $\begin{array}{l}170 \text {-day } \\
110 \text { days post- } \\
\text { boosting }\end{array}$ \\
\hline \multirow[t]{2}{*}{ PBS control } & 1 & 0 & 0 & 0 & 0 & 0 & 0 \\
\hline & 2 & 0 & 0 & 0 & 0 & 0 & 0 \\
\hline $\begin{array}{l}\text { Ave. VNA titers } \\
\quad\left(\log _{2}\right)\end{array}$ & & 0 & 0 & 0.0 & 0.0 & 0.0 & 0.0 \\
\hline \multirow[t]{4}{*}{ pmE2:pFc2 } & 35 & 0 & 3 & 10 & 8 & 6 & 6 \\
\hline & 36 & 0 & 8 & 11 & 7 & 7 & 6 \\
\hline & 38 & 0 & 6 & 10 & 7 & 6 & 5 \\
\hline & 39 & 0 & 5 & $12<$ & 8 & 8 & 7 \\
\hline $\begin{array}{l}\text { Ave. VNA titers } \\
\quad\left(\log _{2}\right)\end{array}$ & & 0 & 5.5 & 10.75 & 7.5 & 6.75 & 6 \\
\hline
\end{tabular}

$V N A$ virus neutralizing antibody, CSFV neutralizing antibody titers were measured as described in the Materials and methods section

economic benefits (Gronberg et al. 2011; Zhang et al. 2017). The most important advantages of the Fc domain are that it increases the half-life of an antigenic peptide in plasma and interacts with $\mathrm{Fc}$ receptors on immune cells, thereby acting as a molecular adjuvant. Taking advantage of these benefits, we produced 302 mg recombinant pmE2 protein from $1 \mathrm{~kg}$ tobacco leaves. This is around tenfold higher than that reported previously using CBD:pmE2 (30.3 mg/kg) (Park et al. 2019). Although the benefits of low manufacturing costs have been mentioned in producing recombinant proteins from plants, there has been much debate due to the lack of research. There are a few technoeconomic analyses for producing recombinant proteins in plants (Buyel anf Fisher 2012; Tuse et al. 2014; Walwyn et al. 2015; Nandi et al. 2016). These simulation reports suggest that cost-effective production with plant expression system can be achieved over alternative platforms although it depends on the products. In addition, high expression of recombinant proteins contributes to lower capital requirements and cost of final products. Therefore, the subunit vaccine based on $\mathrm{pFc} 2$-fused pmE2 chimeric protein can help to provide protection against CSFV at a lower price.

Previous reports show that E2 protein exists as a dimer, as does the Fc domain. However, we found that pFc2:pmE2 was expressed as a multimer. Consistent with this, when CBD-fused E2 was expressed in plants, the product was also multimeric (Park et al. 2019; Sohn et al. 2018). According to size-exclusion chromatography, the protein seemed to form trimer considering that the peak was slightly larger than the peak corresponding to $150 \mathrm{kD}$. However, nativePAGE displayed the band corresponding to tetra or pentamer size. Because the migration of the protein on native-PAGE is affected by diverse factors such as size, folding and isoelectric point, it may not perfectly match with molecular markers. Therefore, more research is needed to establish the structure of pmE2:pFc2, and to examine how it affects the immunogenicity of recombinant proteins and their potential use as vaccines.

In this study, we used pmE2:pFc2 expressing transgenic plants instead of transient expression system. Transient expression generally has been shown to give high amount of target protein than stably expressing transgenic plants (Yamamoto et al. 2018) and we also obtained same results with this fact (data is not shown in here). Thus, assuming that transient expression uses the same biomass, more protein can be produced in a short period and many plant-based pharmaceutical companies are already using the platform. However, there are several reason why we used transgenic plants to produce the recombinant protein. In case of transient expression system, the expression level of target genes is not uniformed. On the other hand, transgenic plant provide stable expression of recombinant genes once the homozygous transgenic lines are generated. This leads to largescale production easier than transient system. In 
economic point of view, upstream processes in transient expression system require additional equipment and material for A.tumefaciens-mediated infiltration while they can be eliminated in transgenic approach, which enables to produce recombinant proteins more inexpensively (Garabagi et al. 2012). Moreover, transient expression system requires additional step to avoid concerns relating to endotoxins that is caused by the use of A.tumefaciens for vacuum infiltration. For these reasons, we think it is more appropriate to use transgenic plants in situations where vaccines must be produced steadily, whereas transient expression system is suitable for urgent situations.

Next, we examined neutralizing antibody responses to CSFV virus in mice and pigs. We found that vaccination of mice and pigs with pmE2:pFc2 generated anti-CSFV neutralizing antibodies. The pig experiments showed a slight increase in the titer of neutralizing antibodies at 20 days post-primary vaccination, and a dramatic increase in titer after the second vaccination. Neutralizing antibody titers were maintained at $6(\log 2)$ until 170 days, although they did fall slightly thereafter. In addition, neutralizing antibodies were readily detectable in mouse serum even at 8 weeks post-vaccination. It is desirable to minimize the number of vaccination to reduce the burden on end users. We confirmed a single vaccination generated antibodies at levels similar to a double vaccination indicating that one-dose injection with 1 $\mu \mathrm{g}$ of pmE2:pFc2 is enough to induce immune responses in mice. Taken together, the results suggest that pmE2:pFc2 induces an efficient neutralized antibody response to CSFV. A limitation is that we vaccinated animals with a single dose $(150 \mu \mathrm{g})$ and used only one type of adjuvant; further studies should vary both parameters to achieve better results. In addition, further studies should address several important issues. For instance, we need to clarify whether vaccination of pigs affects viral shedding and the viral load. Also, we need to examine effects on vertical and horizontal transmission. In other words, it is important to examine whether vaccinated pregnant sows can prevent transplacental transmission of CSFV to the fetus.

We confirmed the presence of anti-pFc2 antibodies in immunized pigs (data is not shown). Antibodies typically contains complex bi-antennary glycans whereas the heterogenous $\mathrm{pFc} 2$ may have high mannose type of glycans due to ER accumulation.
$\mathrm{N}$-glycans at $\mathrm{CH} 2$ domain influence the folding of the Fc part (Mimura et al. 2001). Therefore, it is possible that $\mathrm{pFc} 2$ can be recognized as antigen. Nevertheless, the vaccinated pigs hardly displayed adverse effects during the study. Highly sophisticated approach using glyco-engineering is required for minimizing autoimmune reactions and improved vaccine development based on Fc fragment.

In conclusion, we expressed pmE2:pFc2 in transgenic $N$. benthamiana plants, and isolated and purified the recombinant fusion protein at high yield and low cost. In addition, we confirmed that vaccination of mice and pigs with the fusion protein generated a neutralizing antibody response against CSFV. Taken together, this recombinant protein could be developed as a subunit vaccine against CSFV in a cost-effective manner.

Author contributions EJS designed and organized the overall study. YP and SL wrote the manuscript. HK performed cloning and generated constructs. MP selected and generated transgenic plants. SG, JK, D-JA and SC, organized and carried out pigletrelated work and antibody analysis. KM carried out protein purification and western blot analysis. NK performed ELISA assay and mouse vaccination.

Supporting information Supplemental Table 1-The list of nucleotides sequences used in this study.

Conflict of interest The authors declare that they have no conflict of interest.

Open Access This article is licensed under a Creative Commons Attribution 4.0 International License, which permits use, sharing, adaptation, distribution and reproduction in any medium or format, as long as you give appropriate credit to the original author(s) and the source, provide a link to the Creative Commons licence, and indicate if changes were made. The images or other third party material in this article are included in the article's Creative Commons licence, unless indicated otherwise in a credit line to the material. If material is not included in the article's Creative Commons licence and your intended use is not permitted by statutory regulation or exceeds the permitted use, you will need to obtain permission directly from the copyright holder. To view a copy of this licence, visit http://creativecommons.org/licenses/by/4.0/. 


\section{References}

Ahrens U, Kaden V, Drexler C, Visser N (2000) Efficacy of the classical swine fever (CSF) marker vaccine Porcilis Pesti in pregnant sows. Vet Microbiol 77:83-97

Blome S, Meindl-Bohmer A, Loeffen W, Thuer B, Moennig V (2006) Assessment of classical swine fever diagnostics and vaccine performance. Rev Sci Tech 25:1025-1038

Bouma A, de Smit AJ, de Kluijver EP, Terpstra C, Moormann RJ (1999) Efficacy and stability of a subunit vaccine based on glycoprotein E2 of classical swine fever virus. Vet Microbiol 66:101-114

Bouma A, De Smit AJ, De Jong MC, De Kluijver EP, Moormann RJ (2000) Determination of the onset of the herdimmunity induced by the E2 sub-unit vaccine against classical swine fever virus. Vaccine 18:1374-1381

Buyel JF, Fischer R (2012) Predictive models for transient protein expression in tobacco (Nicotiana tabacum L.) can optimize process time, yield, and downstream costs. Biotechnol Bioeng 109(10):2575-88

Carter PJ (2011) Introduction to current and future protein therapeutics: a protein engineering perspective. Exp Cell Res 317:1261-1269

Cha SH, Choi EJ, Park JH, Yoon SR, Kwon JH, Yoon KJ, Song JY (2007) Phylogenetic characterization of classical swine fever viruses isolated in Korea between 1988 and 2003. Virus Res 126:256-261

Deng MC, Huang CC, Huang TS, Chang CY, Lin YJ, Chien MS, Jong MH (2005) Phylogenetic analysis of classical swine fever virus isolated from Taiwan. Vet Microbiol 106:187-193

Depner KR, Bouma A, Koenen F, Klinkenberg D, Lange E, de Smit H, Vanderhallen H (2001) Classical swine fever (CSF) marker vaccine. Trial II. Challenge study in pregnant sows. Vet Microbiol 83:107-120

Dewulf J, Laevens H, Koenen F, Vanderhallen H, Mintiens K, Deluyker H, de Kruif A (2000) An experimental infection with classical swine fever in E2 sub-unit marker-vaccine vaccinated and in non-vaccinated pigs. Vaccine 19:475-482

Edwards S, Fukusho A, Lefevre PC, Lipowski A, Pejsak Z, Roehe P, Westergaard J (2000) Classical swine fever: the global situation. Vet Microbiol 73:103-119

Garabagi F, McLean MD, Hall JC (2012) Transient and stable expression of antibodies in nicotiana species. Methods Mol Biol 907:389-408

Ghose S, Hubbard B, Cramer SM (2006) Evaluation and comparison of alternatives to Protein A chromatography Mimetic and hydrophobic charge induction chromatographic stationary phases. J Chromatogr A 1122:144-152

Greiser-Wilke I, Fritzemeier J, Koenen F, Vanderhallen H, Rutili D, De Mia GM, Romero L, Rosell R, SanchezVizcaino JM, Gabriel S, A (2000) Molecular epidemiology of a large classical swine fever epidemic in the European Union in 1997-1998. Vet Microbiol 77:17-27

Gronberg A, Eriksson M, Ersoy M, Johansson HJ (2011) A tool for increasing the lifetime of chromatography resins. MAbs 3:192-202

Hua RH, Huo H, Li YN, Xue Y, Wang XL, Guo LP, Zhou B, Song Y, Bu ZG (2014) Generation and efficacy evaluation of recombinant classical swine fever virus E2 glycoprotein expressed in stable transgenic mammalian cell line. PLoS ONE 9:e106891

Huang C (2009) Receptor-Fc fusion therapeutics, traps, and MIMETIBODY technology. Curr Opin Biotechnol 20:692-699

Janeway CA Jr, Travers P, Walport M, Shlomchik MJ (2001) Immunobiology, 5th edn. Garland Publishing, New York

Kim Y, Lee G, Jeon E, Sohn EJ, Lee Y, Kang H, Lee DW, Kim DH, Hwang I (2014) The immediate upstream region of the 5'-UTR from the AUG start codon has a pronounced effect on the translational efficiency in Arabidopsis thaliana. Nucleic Acids Res 42:485-498

Konig M, Lengsfeld T, Pauly T, Stark R, Thiel HJ (1995) Classical swine fever virus: independent induction of protective immunity by two structural glycoproteins. J Virol 69:6479-6486

Kontermann RE (2011) Strategies for extended serum half-life of protein therapeutics. Curr Opin Biotechnol 22:868-876

Laughlin RC, Madera R, Peres Y, Berquist BR, Wang L, Buist S, Burakova Y, Palle S, Chung CJ, Rasmussen MV, Martel E, Brake DA, Neilan JG, Lawhon SD, Adams LG, Shi J, Marcel S (2019) Plant-made E2 glycoprotein single-dose vaccine protects pigs against classical swine fever. Plant Biotechnol J 17:410-420

Levin D, Golding B, Strome SE, Sauna ZE (2015) Fc fusion as a platform technology: potential for modulating immunogenicity. Trends Biotechnol 33:27-34

Lim SI, Song JY, Kim J, Hyun BH, Kim HY, Cho IS, Kim B, Woo GH, Lee JB, An DJ (2016) Safety of classical swine fever virus vaccine strain LOM in pregnant sows and their offspring. Vaccine 34:2021-2026

Lin GJ, Liu TY, Tseng YY, Chen ZW, You CC, Hsuan SL, Chien MS, Huang C (2009) Yeast-expressed classical swine fever virus glycoprotein E2 induces a protective immune response. Vet Microbiol 139:369-374

Lin GJ, Deng MC, Chen ZW, Liu TY, Wu CW, Cheng CY, Chien MS, Huang C (2012) Yeast expressed classical swine fever E2 subunit vaccine candidate provides complete protection against lethal challenge infection and prevents horizontal virus transmission. Vaccine 30(13):2336-2341

Lomonossoff GP, D’Aoust MA (2016) Plant-produced biopharmaceuticals: a case of technical developments driving clinical deployment. Science 353:1237-1240

Luo L, Nishi K, Macleod E, Sabara MI, Lin M, Handel K, Pasick J (2013) Baculovirus expression and antigenic characterization of classical swine fever virus E2 proteins. Transbound Emerg Dis 60(2):143-151

Meyers G, Thiel HJ, Rumenapf T (1996) Classical swine fever virus: recovery of infectious viruses from cDNA constructs and generation of recombinant cytopathogenic defective interfering particles. J Virol 70:1588-1595

Mimura Y, Church S, Ghirlando R, Ashton PR, Dong S, Goodall $M$ et al (2000) The influence of glycosylation on the thermal stability and effector function expression of human IgG1-Fc: properties of a series of truncated glycoforms. Mol Immunol 37(12-13):697-706

Moennig V (2000) Introduction to classical swine fever: virus, disease and control policy. Vet Microbiol 73:93-102 
Nagaya S, Kawamura K, Shinmyo A, Kato K (2010) The HSP terminator of Arabidopsis thaliana increases gene expression in plant cells. Plant Cell Physiol 51(2):328-332

Nandi S, Kwong AT, Holtz BR, Erwin RL, Marcel S, McDonald KA (2016) Techno-economic analysis of a transient plantbased platform for monoclonal antibody production. MAbs 8:1456-1466

Nimmerjahn F, Ravetch JV (2008) Fcgamma receptors as regulators of immune responses. Nat Rev Immunol 8:34-47

OIE (2013) Manual of diagnostic tests and vaccines for terrestrial animals. World Organisation for Animal Health, Paris, pp 1185-1191

Park Y, An DJ, Choe S, Lee Y, Park M, Park S, Gu S, Min K, Kim NH, Lee S, Kim JK, Kim HY, Sohn EJ, Hwang I (2019) Development of recombinant protein-based vaccine against classical swine fever virus in pigs using transgenic Nicotiana benthamiana. Front Plant Sci 10:624

Paton DJ, McGoldrick A, Greiser-Wilke I, Parchariyanon S, Song JY, Liou PP, Stadejek T, Lowings JP, Bjorklund H, Belak S (2000) Genetic typing of classical swine fever virus. Vet Microbiol 73(2-3):137-157

Postel A, Schmeiser S, Perera CL, Rodriguez LJ, Frias-Lepoureau MT, Becher P (2013) Classical swine fever virus isolates from Cuba form a new subgenotype 1.4. Vet Microbiol 161:334-338

Risatti GR, Holinka LG, Fernandez Sainz I, Carrillo C, Lu Z, Borca MV (2007) N-linked glycosylation status of classical swine fever virus strain Brescia E2 glycoprotein influences virulence in swine. J Virol 81:924-933

Rybicki EP (2017) Plant-made vaccines and reagents for the One Health initiative. Hum Vaccin Immunother 13:2912-2917

Sabalza M, Christou P, Capell T (2014) Recombinant plantderived pharmaceutical proteins: current technical and economic bottlenecks. Biotechnol Lett 36:2367-2379

Sohn E, Lee Y, Park N, Park M, Kim N, Park S et al (2018) Development of plant-produced E2 protein for use as a green vaccine against classical swine fever virus. J Plant
Biol 61:241-252. doi:https://doi.org/10.1007/s12374-0180133-4

Thiel HJ, Stark R, Weiland E, Rumenapf T, Meyers G (1991) Hog cholera virus: molecular composition of virions from a pestivirus. J Virol 65(9):4705-12

Tu C, Lu Z, Li H, Yu X, Liu X, Li Y, Zhang H, Yin Z (2001) Phylogenetic comparison of classical swine fever virus in China. Virus Res 81:29-37

Tuse D, Tu T, McDonald KA (2014) Manufacturing economics of plant-made biologics: case studies in therapeutic and industrial enzymes. Biomed Res Int 2014:256135

van Oirschot JT (2003) Vaccinology of classical swine fever: from lab to field. Vet Microbiol 96:367-384

Walwyn DR, Huddy SM, Rybicki EP (2015) Techno-economic analysis of horseradish peroxidase production using a transient expression system in Nicotiana benthamiana. Appl Biochem Biotechnol 175(2):841-854

Weiland E, Stark R, Haas B, Rumenapf T, Meyers G, Thiel HJ (1990) Pestivirus glycoprotein which induces neutralizing antibodies forms part of a disulfide-linked heterodimer. J Virol 64:3563-3569

Yamamoto T, Hoshikawa K, Ezura K, Okazawa R, Fujita S, Takaoka M et al (2018) Improvement of the transient expression system for production of recombinant proteins in plants. Sci Rep 8(1):4755

Yoshikai Y, Matsuzaki G, Inoue T, Nomoto K (1990) An increase in number of $\mathrm{T}$-cell receptor gamma/delta-bearing $\mathrm{T}$ cells in athymic nude mice treated with complete Freund's adjuvants. Immunology 70:61-65

Zhang J, Siva S, Caple R, Ghose S, Gronke R (2017) Maximizing the functional lifetime of Protein A resins. Biotechnol Prog 33:708-715

Publisher's Note Springer Nature remains neutral with regard to jurisdictional claims in published maps and institutional affiliations. 